\title{
Target Cost Contracts and The Development of Collaborative Behaviours and Value for Money in The UK Construction Industry
}

\author{
${ }^{1}$ Smith, A, ${ }^{2}$ Wood, Gerard \\ ${ }^{1,2}$ School of the Built Environment, University of Salford, UK
}

\begin{tabular}{|c|c|}
\hline & ABSTRACT \\
\hline $\begin{array}{l}2016 \text { Research Leap/Inovatus Services Ltd. } \\
\text { All rights reserved. } \\
\text { DOI: } 10.18775 / \text { jibrm.1849-8558.2015.44.3001 } \\
\text { URL: } \underline{\text { http://dx.doi.org/10.18775/jibrm.1849- }} \\
\text { 8558.2015.44.3001 }\end{array}$ & $\begin{array}{l}\text { TCCs are seen to be a procurement model capable of achieving value for money through aligning } \\
\text { the objectives of the parties to reduce costs. The use of Target Cost Contracts (TCCs) within the } \\
\text { UK construction industry has increased dramatically over the past few years. TCCs have been } \\
\text { employed successfully on recent large scale projects such as Heathrow Terminal 5, Crossrail } \\
\text { Procurement Strategy and the } 2012 \text { Olympic Games and Paralympic Games Infrastructure. Due } \\
\text { to the success of TCCs over recent years, many clients are now turning to them in a bid to obtain }\end{array}$ \\
\hline $\begin{array}{l}\text { Keywords: } \\
\text { TCCs, Value for Money, Collaboration, } \\
\text { Incentivise, Target cost, Pain/gain }\end{array}$ & $\begin{array}{l}\text { provide value for money. This research paper investigates the extent to which TCCs promote } \\
\text { collaborative behaviours and provide value for money within the UK construction industry. More } \\
\text { particularly, the research explores the following: which projects TCCs should be used on and } \\
\text { how the maturity of the design when agreeing the target cost can affect value for money; how } \\
\text { setting both the target cost and the pain/gain mechanism can affect the incentivisation of the } \\
\text { contractor to minimise costs; the extent to which TCCs promote collaboration between the } \\
\text { contractor, client and supply chain; and what is required to manage a TCC post-contract to ensure } \\
\text { that incentivisation is maintained. It has become apparent from the research that TCCs are } \\
\text { complex procurement models which require extensive consideration and management to ensure } \\
\text { parties are incentivised to minimise costs. The research reveals that although TCCs can promote } \\
\text { collaborative behaviours and provide value for money, there is a prerequisite to doing so: } \\
\text { developing and managing the TCC correctly to ensure that the objectives of the parties are } \\
\text { aligned. }\end{array}$ \\
\hline
\end{tabular}

\section{Introduction}

\subsection{Background}

Incentivisation contracts have long been used in the UK construction industry in order to align the objectives of the parties to a construction contract to achieve better performance. A TCC is a type of incentive contracting commonly used on projects within the UK construction industry. TCCs seek to align the objectives of the parties which helps create a collaborative environment (Bresnen and Marshall, 2000). TCCs were created for use on large infrastructure projects which were complex and high risk due to unknown ground conditions (Heaphy, 2011). Due to their success on these projects their use has grown year on year with standard TCC forms of contract such as the NEC options C and D being established.

TCCs are associated with reimbursable contracts as the contractor is reimbursed the actual defined costs incurred in carrying out the works. However, unlike reimbursable contracts, the financial risks of projects are shared by both the contractor and client through the use of a pain/gain mechanism.
A pain/gain mechanism is employed so that any underspend or overspend against the pre-agreed contractual target cost is shared between the parties. If the actual costs are lower than the target, the client and contractor will share the savings based on the pre-agreed share ratio. Conversely, if the actual costs exceed the target, both parties will share any overspend based on the pre-agreed share ratio. The sharing of risk through the pain/gain mechanism should actively encourage parties to collaborate to manage and reduce costs to a minimum (Lewedon, n.d. \& RICS, 2014).

During recent years, TCCs have become increasingly popular within the UK construction industry as clients look to obtain value for money through incentivising contractors (RICS, 2017). The UK Government Construction Strategy recognises TCCs as a cost led procurement model capable of producing the $15-20 \%$ cost savings required for public sector construction projects by 2015 (Cabinet Office, 2012). TCCs have successfully provided value for money on a variety of recent major projects such as Heathrow Airport Terminal 5, Crossrail Procurement Strategy and the 2012 Olympic and Paralympics 
Games Infrastructure. However, they have also proved unsuccessful on other projects. Within AMEC v Secretary of State for Defence (2013), value for money was not achieved and disputes arose over who was liable to pay cost overruns above the Guaranteed Maximum Price Target Cost (RPC, 2013).

Although it is understood that TCCs in theory should reduce costs through aligning the objectives of the parties, often clients are disillusioned with the financial outcome of TCCs. As the popularity of TCCs has grown in the UK construction industry, clients are questioning whether they really do provide value for money. It seems that it is only in certain circumstances where prerequisites are met, that TCCs promote collaboration and provide value for money. Clients need to be fully aware of the implications of TCCs and the requirements to provide value for money prior to using them.

\subsection{Aims and objectives}

The overall research aim is to investigate the extent to which TCCs promote collaborative behaviours and provide value for money in the UK construction industry. The objectives of this research are: to explore which projects are suitable for use with a TCC and how the development of design can affect value for money when agreeing the target cost; analyse how setting the target cost and pain/gain mechanism can affect the incentivisation of the contractor to reduce costs; analyse whether TCCs promote collaboration between the client and contractor, and the whole supply chain; and to explore what is required to manage a TCC post-contract award to maintain incentivisation.

In order to achieve the aim of this research paper, the methodology included a literature review of a large body of existing literature. The pre-existing literature has been examined and analysed to build the argument that TCCs do promote collaboration and provide value for money, but only when parties fully understand the contract process.

\section{Critical Review of Literature}

\subsection{Introduction}

This part of the research paper has been split into four sections. The first section looks at which projects are appropriate for TCCs and how the level of design at the time the target cost is agreed influences value for money. The second section looks at how setting the target cost itself and the pain/gain mechanism can influence value for money through aligning the objectives of the parties. The third section looks at the extent to which TCCs can influence collaboration. The final section explores what is required post-contract award to ensure that collaboration and incentivisation are maintained to achieve value for money.

\subsection{Value for Money in Target Cost Contracts}

TCCs intend to promote collaboration and provide value for money through incentivising the contractor to control costs. The main constituents of TCCs include the target cost, the fee and the share formula (Perry \& Thompson, 1982). The target cost is agreed between both parties normally through a competitive procedure and should reflect a best estimate of likely outturn costs to deliver the scope of work. The fee covers overheads and profit for the contractor and is normally a fixed percentage. The share formula introduces the incentive into the contract by determining how any savings or cost overruns against the target cost will be shared between the parties. Scottish Futures Trust [SFT] (2016, p30), within their review of Scottish public sector procurement, state that "the principle benefit of target cost arrangements is their ability to align the objectives of the parties, which helps to create a partnering environment". Further, they argue that as objectives are aligned, the parties are encouraged to work together to control costs, sharing the risk through the pre-agreed pain/gain mechanism.

In order to achieve value for money on any project, the most appropriate contract needs to be selected. A study of the use of TCCs was undertaken by Perry and Thompson (1982) within the CIRIA 85 report which is still very influential within the field today. Within this report, they identify that high risk projects where costs are likely to escalate are appropriate for TCCs. This is because TCCs offer more flexibility in terms of change than typical fixed priced contracts. Broome (1999), who has provided influential literature on TCCs, agrees with Perry and Thompson that TCCs are appropriate for projects when a high level of design change is anticipated and thus flexibility is required. It is also suggested by various sources that TCCs are not suitable for low value contracts as they contain the burden of high administrative costs through the use of unfamiliar administrative procedures such as open book accounting (Broome, 1999; Lewedon, n.d.; Hughes \& Gruneberg, 2009). Therefore, for smaller projects with minimal to medium levels of risk, clients should look to use alternative contracting models to provide value for money.

Within the literature, there is no general consensus on how defined the scope of works/design needs to be at the point the target cost is calculated. Various sources suggest that TCCs can be useful and may be the most appropriate contract where the extent of work to be carried out has not been fully defined (Broome, 1999; McInnis, 2001; Fenwick Elliot, 2016). The reason behind this argument is that a target cost can be agreed based on an initial specification and can be amended following confirmation of the final specification following contract award. Heaphy (2011) recognises that as work can commence based on an initial design and target cost, earlier starts on site can be achieved when compared with traditional lump-sum contracts. This can provide value for money to the client as the project should in theory finish earlier if a TCC is selected over a lump-sum contract.

Conversely, a different view established within the literature is that value for money will only be secured if the contract is let with a well-defined target cost to enable the contractor to be able to price the works accurately (SFT, 2016; Lewedon, n.d.; International Law Office, 2003). Rawlinson (2007) agrees with this viewpoint that value for money is not achieved on insufficiently defined projects. He suggests that TCCs should be used on well-defined projects with a full set of works 
information as loosely defined projects provide the contractor with the opportunity to renegotiate the target cost through design amendments. Research undertaken by Tirole (1986) demonstrates that contractors will be less incentivised to minimise costs if there are future opportunities to renegotiate the target cost. Brumm (1992) further develops this viewpoint, suggesting that TCCs in fact incentivise contractors to propose frequent modifications in order to increase the target instead of reducing actual costs. Where this is the case value for money will be significantly compromised.

Drawing on the research, it needs to be recognised that a sufficient level of design does need to be defined to allow a target cost to be agreed which reflects a best estimate of likely outturn costs. Although Broome (1999) suggests that TCCs are suitable for contracts where the extent of work is not fully designed, he does highlight that the scope of work still needs to be 'sufficiently' developed. If the scope of work is insufficiently developed, then the contractor will have numerous opportunities to renegotiate the target cost and may subsequently focus their efforts on increasing the target to maximise gain-share potential rather than creating efficiencies. Moreover, TCCs which involve large amounts of scope change present significant risks to the client in terms of value for money. This is because if the scope and value of contract changes significantly so that changes are assessed retrospectively, then TCCs can easily become fully reimbursable contracts (Broome, 1999). Value for money is not achieved on reimbursable contracts as the contractor is not incentivised to control costs. Therefore, although the design does not need to be complete, clients should ensure that they have an adequate level of design to enable a target cost to be set that, although may need firming up as the design is finalised, will not require drastic changes.

Furthermore, value for money can also be affected on TCCs by reduced quality standards as a consequence of contractors trying to minimise costs to increase gain-share potential. Kwawu and Laryea (2013) argue that with cost often being the biggest element of risk in contracting, incentivisation contracts tend to focus on cost which impacts other areas of the project. Both quality and time become less important than completing under the target cost and subsequently these aspects of TCCs can be neglected. Contractors may look to rush work, reduce quality of materials or use in-experienced and cheaper resources to minimise costs. In the long term this can affect value for money due to higher maintenance and repair costs. To the contrary, Perry and Thompson (1982) and McInnis (2001) argue that quality and time are also principle elements which clients wish to control through the use of TCCs. This is because in order to minimise costs, contractors are incentivised to complete on time and to maintain quality standards through minimising defects. As pre-completion defects form part of the defined cost, but do not constitute an increase to the target cost, the contractor is incentivised to keep defects to a minimum to increase gain-share potential (Fenwick Elliot, 2016). Therefore, although cost is the main focus, both time and quality should not be adversely impacted as a result of using TCCs.

\subsection{Setting the Target Cost \& Pain/Gain Mechanism}

The target cost and pain/gain mechanism are fundamental in aligning the objectives of the parties and driving the right behaviours to reduce costs and obtain value for money. It is therefore vital that clients understand the implications of setting target costs and pain/gain mechanisms.

\section{$\underline{\text { Target Costs }}$}

Within his paper to the Society of Construction Law, Heaphy (2011, p.1) a partner at EC Harris Law firm, defines a target cost as a "genuine pre-estimate of the most likely outturn cost for the project, as defined in the contract documentation". Target costs need to reflect the best estimate of probable cost in order to offer a genuine incentive to the contractor (Perry \& Thompson, 1982). A realistic target cost plays an essential role in ensuring the opportunity to achieve savings that will benefit both parties (Pinsent Masons, 2016 \& Fenwick Elliot, 2016). It is argued that TCCs will only provide value for money when the target cost is set at a level that requires the client and contractor to collaborate to create efficiencies which are beyond those that are normally expected (SFT, 2016 \& Heaphy, 2011).

When setting the target cost, there are various issues that clients need to consider. The following figure illustrates three different scenarios that can occur when setting target costs.

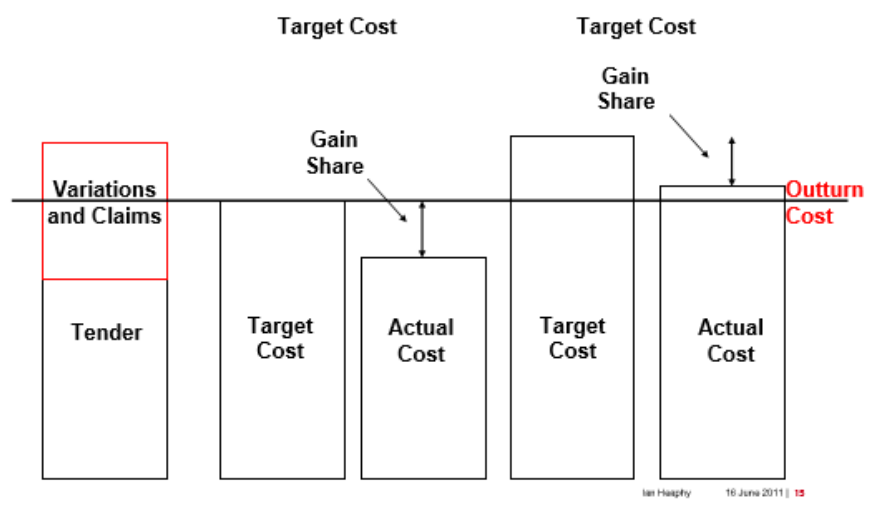

Figure 1. - Setting the Target Cost (Heaphy, 2011, p.4)

In scenario 1 in figure 1 , in order to win the contract the contractor provides a target cost (tender) which is below a genuine estimate for likely outturn costs (annotated in red). Once the contractor is awarded the contract, they will look to increase the target so that it reflects likely outturn costs (annotated in red) or even above through variations and claims. The high number of variations and claims will cause adversarial relationships between the parties to develop and will distract both parties from focusing on creating efficiencies. The additional administration costs in preparing and assessing variations and claims will increase actual costs and subsequently reduce value for money. Moreover, Rawlinson (2007) suggests that if the target is too low, the contractor may look to seek to recover costs through alternative methods other than raising the target. Rawlinson states that a contractor may look to increase actual costs above the target cost in order to recover costs through additional fee. It also needs to be recognised that some contractors are motivated to secure certainty of yield on TCCs by increasing the value of fee when 
negotiating the target (Perry \& Barnes, 2000). Consequently, clients need to assess both the level of fee and the target cost in order to ensure value for money.

In addition, some clients believe they are gaining value for money by beating down target costs. However, in reality, doing so removes any incentivisation for the contractor to control costs (Fenwick Elliot, 2016). In fact, Perry \& Thompson (1982) suggest that beating down the target results in the removal of positive behaviours from the contractor and promotes the wrong behaviours. Subsequently, instead of aiming to lower the target cost as much as possible which can damage relationships, clients should ensure that the target cost reflects a best estimate of likely outturn costs. Scenario 2 in figure 1 shows a target cost which represents a best estimate of likely outturn cost. With a genuine target that reflects the scope of work, the contractor can focus on creating efficiencies to increase potential gain-share. Value for money is likely to be obtained in scenario 2 as both parties are focusing on creating efficiencies.

Scenario 3 in figure 1 however will not provide value for money to the client. In this scenario, the target cost agreed does not represent a best estimate of likely outturn cost (annotated in red) as it is overinflated. Wamuziri and Seywright (2005) recognise that creating efficiencies on TCCs is not the only way contractors can maximise their payoff. They suggest that seeking an inflated target, illustrated in scenario 3, helps maximise payoff. Clients need to be wary of inflated target costs as they remove any incentive for the contractor to create efficiencies and subsequently impair value for money. Inflated targets may reward the contractor through gain-share for ordinary or poor performance, completing the work at the expected outturn cost or even above (Heaphy, 2011).

Furthermore, in order to achieve value for money on TCCs, clients require sufficient knowledge and experience to be able to accurately estimate the likely outturn costs of the project (Designing Buildings Wiki, 2017). Fisher (1969) in his evaluation of incentive contracting in the defence sector recognises that more accurate methods of determining target costs will increase value for money potential rather than elaborative incentive sharing arrangements. In order to obtain an accurate target cost, clients need "good cost reporting information systems from historical projects, improved costs analysis and estimating capability" (Wamuziri \& Seywright, 2005). In addition, in order to ensure the target is robust, clients should seek to use experts to challenge the costs provided by the contractor (Heaphy, 2011).

\section{Pain / Gain Share}

Heaphy (2011) and SFT (2016) both recognise that the pain/gain mechanism is the key driver in achieving value for money and contractor efficiency in TCCs. The pain/gain mechanism is tantamount in aligning the objectives of the parties to reduce costs and therefore it is essential that clients understand the implications of setting the pain/gain mechanism (Heaphy, 2011). Within the literature, there is no general consensus on the ideal sharing ratio to achieve value for money. Weitzman (1980) suggests that the optimal sharing ratio depends on the contractor's ability to reduce costs, risk aversion and project uncertainty.

The most common share ratio adopted is a straight 50/50 split between the contractor and client. A large body of research advocates that clients should avoid setting the contractor's share at less than $50 \%$ as this removes any incentivisation for the contractor to control costs (Weitzman, 1980; Perry \& Barnes, 2000; T. Williams, M. Williams \& Ryall, 2013; Broome, 1999; \& Heaphy, 2011). The reason being is that contractors will not be incentivised to create efficiencies if savings are not shared on an equal basis (Pinsent Masons, 2016). If a share percentage less than $50 \%$ is allocated to the contractor, they may look to increase the target cost to maximise pay off instead of focusing on creating efficiencies. Heaphy (2011) also argues that the straight 50/50 split is the simplest share method that helps to drive partnering behaviours as the risk is shared equally. If the share formula is weighted in favour of one party, then the incentive power can be effected as parties are not seen to be working equally (T. Williams, M. Williams \& Ryall, 2013).

Research undertaken by Wood (2005), within an RICS research paper which involved interviews with 10 national contractors, highlights examples of TCCs where clients had implemented unfair sharing mechanisms which were considered to contradict the spirit of partnering. Within the research, one contractor provided an example of where all underspend against the target cost was allocated to the client. Where this is the case, the contractor will not be incentivised to create efficiencies and consequently both collaboration and value for money will be jeopardised.

When considering a straight 50/50 split, clients need to determine the contractor's potential to reduce costs. Weitzman (1980) argues that where the contractor has great potential to reduce costs through contributing to the development of the design, then they should benefit from a share ratio above $50 \%$. To the contrary, Broome (2002) believes that if there is limited potential for the contractor to provide large costs savings then the split should also be above $50 \%$ to motivate contractors. Although clients need to ensure that contractors have the potential to reduce costs, they also need to ensure that the potential is limited in order to motivate the contractor to create efficiencies which are beyond those normally expected. To create efficiencies beyond those normally expected, clients should ensure that value engineering has been undertaken prior to agreeing the target cost and share ratio.

Clients also need be aware of the potential ability of other stakeholders to reduce costs. Perry and Thompson (1982) suggest that the engineer or designer has a considerable influence on the execution of a contract and subsequently can affect the ability of a contractor to meet a target. Subsequently, Perry and Thompson (1982) suggest that engineers are linked into the pain/gain mechanism. However, T. Williams, M. Williams and Ryall (2013) argue that linking numerous parties into the pain/gain mechanism contractually can be complex and 
time consuming which can reduce value for money. It is therefore advisable that clients should only look to include designers and subcontractors into the sharing mechanism if they have a substantial potential to reduce costs, otherwise value for money could be compromised.

Moreover, although most contractors will usually request a share ratio above $50 \%$, this is not always the case. This is because a straight 50/50 split can affect a contractor's profit margin if the actual costs far exceed the target (Perry and Thompson, 1982). Therefore, on high risk projects, contractors may not want to bear the risk associated with a $50 \%$ split, especially where the contractor's potential to control costs is limited. Enforcing a 50\% split on a high risk project, where the contractor has limited potential to control costs will result in less value for money. This is because the target cost will be inflated with risk due to cost uncertainty. In addition, the contractor will look to renegotiate the target cost through claims and variations in order to further reduce his risk of overspend. Subsequently, when setting the share ratio, client's need to consider the contractors risk aversion as implementing a high ratio could significantly impair value for money depending on the organisation.

Broome (1999), within his previous research has advocated that the contractor's share not be less than $50 \%$. Despite this and contrary to the views of others (Weitzman, 1980; Heaphy, 2011; Perry and Barnes, 2000), Broome (2013) now suggests that this may not always be the case. Developing on his previous research, Broome (2013) now suggests that where the client is larger than the contractor and is better able to carry the risk, then the cost overrun above a certain percentage should entirely lie with the client. Alternatively, if the contractor is a large organisation, then it may be advisable to cap the over run at $100 \%$ to the contractor as they have the financial capacity to bear the risk (Broome, 2013). Where the over spend is fully allocated to the contractor the contract becomes a guaranteed maximum price (GMP) contract. It needs to be recognised that where there is a GMP, once the contractor is perceived to complete the project above the target cost, the client will be substantially less motivated to reduce costs (Broome and Perry, 2002). Where this happens, collaboration and value for money will be impaired as disputes are likely to arise if the contractor feels they are entitled to an increase to the target cost to limit their pain exposure.

Clients also need to consider whether they intend to work with the same contractor in the future on similar projects. Wood (2005) suggests that clients who are going to work with contractors on future schemes tend to be more generous when setting the share ratio because of the potential to replicate any savings on subsequent projects. Increasing the contractor's share will incentivise the contractor to create efficiencies on the first project which will benefit the client in terms of value for money on future schemes.

It can be concluded from the research that setting the share ratio is complex and requires a substantial amount of consideration. Clients need to provide sufficient time to review the impact of different share ratios in order to ensure that the optimum share ratio is employed that aligns the objectives of the parties to provide value for money.

\subsection{Collaboration in Target Cost Contracts}

Collaboration is a key success factor in ensuring value for money is achieved on projects. There is a strong consensus in the existing literature suggesting that TCCs promote collaboration in projects. Various studies (Perry \& Thompson, 1982; Heaphy, 2011; Broome, 1999) highlight that the principle benefit of target cost arrangements is their ability to align the objectives of the parties, which helps create a partnering environment and a resulting identity of interest. Further studies (Hughes, T. Williams \& Zhaomin, 2012; Constructing Excellence, 2011; Bresnen \& Marshall, 2000) also suggest that target cost arrangements deliver value for money through creating a collaborative working environment by aligning the objectives of the parties. The contractor is aligned to the client's objective to minimise costs in order to increase their profit margin.

Conversely, research undertaken by T. Williams, M. Williams and Ryall (2013), which involved interviews with industry professionals who have experience managing TCCs, disagrees with this general consensus by suggesting that TCCs create a misalignment of objectives between the client, contractor and design team as parties are motivated for different things. This is because the client is motivated by cost, time and quality, the contractor just profit and the design team just quality. In order for collaboration to occur and thus value for money, clients need to ensure that the objectives of all key stakeholders are aligned. Although the research undertaken by T. Williams, M. Williams and Ryall (2013) involved personnel experience of interviewees, and therefore does not represent all professional views, the professionals interviewed had years of experience managing TCCs and therefore their direct experience is important to consider. Therefore, in order to align the client's time objective to the contractor, clients should look to use bonus payments or liquidated damages. In order to incentivise the design team and main subcontractors to reduce costs, clients should include the design team and main subcontractors into the contractual pain/gain mechanism.

When the objectives between parties are aligned in TCCs, they should reduce conflict and adversarial relationships associated with other types of contracts. McInnis (2001) argues that TCCs promote teamwork, in replacement of the traditional adversarial relationships and claims conscious attitudes normally associated with traditional procurement methods. Further, numerous studies (Kawau \& Laryea, 2013; Eriksson, Atkin \& Nilsson, 2009) argue that the sharing of risk and the high level of cooperation associated with TCCs reduces the occurrence and opportunity of conflicts and disputes occurring.

The high level of cooperation present in TCCs stems from the use of open book accounting which enables trust to be built between the parties. Perry and Thompson (1982) argue that the use of open book accounting on TCCs reduces the number of claims greatly and simplifies the resolution of claims that do occur. The openness of information through open book accounting increases confidence and should lead to greater 
collaboration through the closer alignment of motivation (Perry $\&$ Barnes, 2000). In addition, as the client has access to the accounts and records of the contractors actual costs, agreeing variations is easier and less confrontational than with other forms of contract (Heaphy, 2011). Heaphy also suggests that open book accounting will deter contractors from wasting time applying for claims which cannot be justified and will instead focus this time on seeking efficiencies, thus providing value for money. Subsequently, it can be concluded that the use of open book accounting should in theory reduce disputes due to a greater level of collaboration.

Although there is a large body of research recognising TCCs ability to promote collaboration, there are various sources that believe TCCs promote adversarial behaviours. SFT (2016) and Fenwick Elliot (2016) suggest that the use of open book accounting can in fact cause disputes and adversarial behaviours to occur when the client scrutinises the contractor's cost records to ensure they are valid. As the client has access to the contractor's cost records, difficulty can arise when agreeing variations if the contractor submits a quotation inflated with risk to increase the target cost and thus potential gainshare. Broome (1999) recognises that where this is the case, the objectives and motivations of the parties are not aligned.

Similarly, T. Williams, M. Williams and Ryall (2013) agree with the aforementioned sources that TCCs can promote adversarial behaviours by suggesting there is a need for the contractor to be claims conscious. This statement can be explained by referring back to scenario 1 in figure 1 where the contractor submits a low target cost to win the work. With a low target, the contractor will try to increase the target cost through overinflated variations and claims. Consequently, it can be argued that TCCs which contain low targets will discourage collaboration and promote adversarial relationships as there will be an increased number of claims and disputes put forward by the contractor. Therefore, as aforementioned, it is imperative that target costs are not set too low as doing so will drive the wrong behaviours which will impair value for money.

It is also needs to be recognised that TCCs require clear definitions of what is payable and disallowable under the contract. If the contract does not define payable and disallowable costs then disputes are likely to arise. Therefore, is it essential that the contract explicitly states what is payable in order to promote collaboration and reduce disputes and claims.

It can be concluded that when the target cost and share ratio are set at a level which encourages the contractor to reduce costs, collaboration will increase due to the alignment of objectives. However, Rose and Manly (2010) recognise that although TCCs are intended to promote collaboration in the whole supply chain, a criticism in the published literature is that they only incentivise the client and contractor only. Other sources (SFC, 2016 \& Rawlinson, 2007) suggest that TCCs incentivise the contractor, subcontractors and suppliers to reduce costs and promote collaboration in the whole supply chain. Although TCCs can incentivise all of the aforementioned parties, SFT and
Rawlinson do not state how this can be achieved. T. Williams, M. Williams and Ryall (2013) recognise that to deliver a gain under a TCC it requires collaboration not just between the contractor and client but also between the consultants, subcontractors, design team, supply chain and manufacturers. This is because TCCs do not incentivise other stakeholders to minimise costs if they are not linked into the share ratio. Subsequently, in order to incentivise the key stakeholders, who have a high potential to reduce costs, they need to be linked into the share ratio to benefit from creating efficiencies. This will ensure that all key players who can affect cost performance are motivated to control costs, thus providing value for money.

\subsection{Managing Target Cost Contracts Post Contract Award}

The previous sections within this paper have predominantly focused on how pre-contract activities affect value for money on TCCs. However, clients need to recognise that post-contract management on TCCs is essential in providing value for money. Without good TCC post-contract management, incentivisation to control costs will be lost and value for money will be jeopardised.

In order to achieve value for money, clients need to recognise that TCCs involve the client carrying a greater amount of risk than they would do with conventional priced contracts (Perry \& Barnes, 2000). Often, problems arise where the client does not realise they are carrying a greater amount of risk than compared with a fixed price contract. They then do not manage this additional risk properly. This can result in the target cost not being amended to reflect scope, and subsequently the share mechanism becoming invalid. Where this occurs the contract may revert to an entirely reimbursable basis and value for money will be jeopardised (SFC, 2016). To prevent this from happening, clients need to be aware that TCCs involve clients bearing greater risk than fixed priced contracts and therefore require greater amount of resources to manage post-contract.

Furthermore, as TCCs are a complex contracting mechanism, which are administratively heavy, they require competent project managers as effective project management is a key instrument in ensuring benefits are realised by both parties (Fenwick Elliot, 2016 \& Rawlinson, 2007). A common issue that inhibits value for money on TCCs is recognised by Perry and Thompson (1982) who suggest that site personnel who lack proper TCC training may not understand the significance of the target cost and may subsequently treat and manage the contract as if it were reimbursable. Further, the administrative demands of TCCs create a risk that the link between the target cost and actual cost could be lost and the client could be exposed to a significant transfer of risk (Rawlinson, 2007). As a result, in order to maintain incentivisation and value for money potential, it is essential that competent professionals who have experience and training on how to manage TCCs are employed.

Broome and Perry (2002) highlight that the use of open book accounting on TCCs places an extra burden on the client in terms of administration costs as additional time is required to assess subcontractors, types of resources and calculation of productivities. Other studies (T. Williams, M. Williams and Ryall, 2013; Lewedon, n.d.; Chan et al, 2011) agree with 
Broome and Perry, proposing that TCCs are often criticised for the additional time and cost required for administration due to unfamiliar administration procedures such as open book accounting which impair value for money. They agree that greater client involvement is essential in TCCs and that competent professionals are required. If good purchasing and post-contract management are not present on TCCs then value for money will be impaired as incentivisation will not be maintained.

Although the previous sources referred to suggest that TCCs increase administration costs, Perry and Thompson (1982) believe that TCCs can in fact reduce administration costs in comparison with other procurement models. They suggest that due to the improved facility for evaluating change and the greater collaboration between the parties, the protracted negotiation of claims should be reduced. Therefore, it can be argued that although TCCs are resource intensive, they may actually be less resource intensive when compared with fixed priced contracts where great amounts of change are present. This is because open book accounting should allow for easier agreement of variations and the final account and should therefore reduce the number of disputes as compared with fixed priced contracts whereby the client does not have access to the contractor's records.

The most important factor in maintaining incentivisation postcontract is to ensure that the target cost remains visible to the contractor. To do so, clients need to ensure that the target is adjusted for variations so that it reflects the latest scope of work. Heaphy (2011) highlights that in order to maintain the target cost; changes need to be agreed as soon as they occur. A key factor which is often neglected in managing TCCs is agreeing change as soon as it occurs. Not agreeing change prior to or at the time it occurs means that the increase to the target cost will be based on actual costs incurred. If the target is being increased based on actual costs, the contractor will not be incentivised to create efficiencies and the contract essentially becomes fully reimbursable. Target costs which are unmaintained for long periods and do not reflect actual scope can result in the sharing mechanisms becoming invalid. Where this occurs, the contract will revert to an entirely reimbursable basis and value for money will be impaired.

Moreover, it is fundamental that both parties understand what constitutes a legitimate change to the target cost under the contract to reduce the potential of claims and disputes occurring. The contract needs to identify the risks which the contractor cannot manage and are therefore at the client's risk. These client's risks need to be clearly stipulated in the contract documentation and if any materialise, the contractor shall be entitled to an increase to the target (Broome, 2002). In addition, Perry and Barnes (2000) highlight that the project manager needs to be fair when assessing target cost adjustments as reliable and fair methods of target adjustments are an important component of successful TCCs. They also highlight the importance of precise and clear definitions of actual cost and fee within the contract. Doing so will reduce the administrative costs in time spent preparing and rejecting claims and time spent disallowing costs in payment applications.

\section{Conclusion}

In summary, this paper has investigated the extent to which TCCs promote collaborative behaviours and provide value for money in the UK construction industry. The following part of the conclusion revisits the research objectives of this paper and summarises the findings of the research work.

\section{Objective 1;}

Explore which projects are suitable for use with a TCC and how the development of design can affect value for money when agreeing the target cost. The literature review has revealed that TCCs are favourable to provide value for money when used on high risk, complex and large projects where change is likely to occur. The flexibility that TCCs provide will enable change to be administered more efficiently than if a fixed price contract is selected. Value for money will be compromised when using TCCs on simple, low value and low risk projects due to the complexity of the contract and high administrative burdens.

This paper further recognises that TCCs are useful contracting models for projects where the design has not yet been finalised. However, it has become apparent that ensuring an adequate level of design is completed prior to going out to the market will enable a contractor to provide a more accurate target cost. Further, the more developed the design, the fewer opportunities the contractor will have to renegotiate the target cost. Subsequently, they will be more focused on creating efficiencies and providing value for money rather than seeking to increase the target.

\section{Objective 2;}

Analyse how setting the target cost and pain/gain mechanism can affect the incentivisation of the contractor to reduce costs. The literature review has revealed that value for money is likely to be achieved on projects where the target cost is set at a level which reflects a genuine pre-estimate of the most likely outturn cost for a project. Doing so incentivises the contractor to focus on creating efficiencies to increase gain-share potential. Target costs that are too low and are over inflated with risk cause the objectives of the parties to become unaligned and thus value for money will be impaired.

It is evident that the pain/gain mechanism is the core driver of aligning the parties' objectives to work collaboratively to achieve value for money. There are a variety of share ratios that can be employed and the optimal share ratio depends on the project conditions. The research has revealed that there is a strong consensus advocating that the share ratio to the contractor not be set any less than $50 \%$ as doing so removes incentivisation to reduce costs. Further, it appears that adopting a straight 50/50 split may be the most desirable share ratio due to the simplicity and impartiality of sharing risk equally. However, clients need to recognise that a $50 \%$ share ratio may not always be the optimum share ratio to promote collaboration and provide value for money. Clients need to consider the contractor's ability to reduce costs, risk aversion and project uncertainty to ensure that the optimal share ratio is employed. 
The research has also identified that in certain projects, it may be necessary to incentivise all key supply chain members including the design team through the pain/gain mechanism if they have a strong potential to reduce costs. However, this paper has not analysed how far down the supply chain the share ratio should be employed. It has become apparent that this is an area for further research and consideration.

\section{Objective 3;}

Analyse whether TCCs promote collaboration between the client and contractor, and the whole supply chain.

The research suggests that there is a strong consensus that TCCs do promote collaborative behaviours: reducing conflict, disputes and adversarial relationships. The literature suggests that collaboration prospers through the alignment of the objectives of the parties through the pain/gain mechanism and through the use of open book accounting. However, the research also recognises that collaboration can be significantly impaired when the objectives of the parties become unaligned. The research suggests that TCCs promote collaborative behaviours when: the target cost reflects a best estimate of likely outturn costs; the pain/gain mechanism aligns the objectives of the parties; open book accounting is not abused through clients scrutinising cost records; the contract explicitly defines payable and disallowable costs; and the contract explicitly states what constitutes a change to the target cost. It needs to be recognised that although TCCs provide the foundation for collaboration to prosper, collaboration still relies upon the willingness of personnel to co-operate.

Furthermore, this research has highlighted that TCCs often do not promote collaboration throughout the supply chain. Many contracts are let with only the contractor and client linked into the pain/gain mechanism. It has become apparent that on certain projects other stakeholders have a strong potential to reduce costs. Subsequently, not including these key stakeholders into the share mechanism drives the wrong behaviours and can significantly impair value for money.

\section{Objective 4;}

Explore what is required to manage a TCC post-contract award to maintain incentivisation and obtain value for money.

It is evident that good contract management on TCCs is a fundamental requirement in ensuring value for money. Clients need to recognise that they are bearing a greater amount of risk with a TCC than they would be with a fixed priced contract. Thus, competent resources are required to manage the contract and ensure that the target cost is maintained. This involves agreeing change as soon as it occurs to ensure that the target cost reflects the scope of work and the pain/gain mechanism remains valid.

The overall conclusion that can be drawn from the research is that TCCs are a complex procurement model which are capable of promoting collaborative behaviours and providing value for money in the UK construction industry but only when they are developed and managed correctly to ensure that the objectives of the parties are aligned. Further research and consideration is required on this subject in order to establish further how clients can align the objectives of all key parties to achieve value for money.

\section{References}

- Bresnen, M. and Marshall, N. (2000). Motivation, commitment and the use of incentives in partnerships and alliances. Construction Management and Economics, 18(5), 587-98. Crossref

- Broome, J. (1999). The NEC Engineering and Construction Contract: A user's guide. London: Thomas Telford Publishing.

- Broome, J. (2002). Procurement Routes for Partnering: A Practical Guide. London: Thomas Telford Publishing. Crossref

- Broome, J. and Perry, J. (2002). How practitioners set share fractions in target cost contracts. International Journal of Project Management. 20, 59-66. Crossref

- Broome, J. (2013). How to intelligently set the Contractor's share percentages and share ranges. Retrieved 20 February, 2017, from https://builtintelligence.com/blogs/opinionsblog/9101211-how-to-intelligently-set-the-contractor-sshare-percentages-and-share-ranges

- Brumm, H., J. (1992). Incentives in incentive contracting: an application of the MIMIC model. Applied Economics, 24, 337-345. Crossref

- Cabinet Office. (2012). Government Construction Strategy: Final Report to Government by the Procurement / Lean Client Task Group, July 2012.

- Chan, D., W., Chan., A., P., Lam, P., T., \& Wong, J., M. (2011). An empirical survey of the motives and benefits of adopting guaranteed maximum price and target cost contracts in construction. International Journal of Project Management., 29, 577-590 $\underline{\text { Crossref }}$

- Constructing Excellence. (2011). The business case for lowest price tendering. Retrieved 20 March, 2017, from http://constructingexcellence.org.uk/wpcontent/uploads/2015/01/CE-business-case-against-lowestprice-tendering-May-2011.pdf

- Designing Buildings Wiki. (2017). Target cost for construction. Retrieved 18 February, 2017, from https://www.designingbuildings.co.uk/wiki/Target_cost_fo r_construction

- Eriksson, P., Atkin, B., and Nilsson, T. (2009). Overcoming barriers to partnering through cooperative procurement procedures. Engineering, Construction and Architectural Management, 16(6), 598-611. $\underline{\text { Crossref }}$

- Fenwick Elliot. (2016). NEC 3 and Target Cost Contracts: Defined Costs, Disallowed Costs and Defects. Retrieved 20 March, 2017, from http://www.fenwickelliott.com/researchinsight/newsletters/insight/62

- Fisher, I., N. (1969). An evaluation of incentive contracting experience. Naval Research Logistics Quarterly, 16(1), 6383. Crossref

- Heaphy, I. (2011). Do Target Cost Contracts Deliver Value for Money? A paper presented to the Society of Construction Law. Society of Construction Law.

- Hughes, W. and Gruneberg, S. (2009). Review of Performance-Based Contraction, Reading: School of Construction Management and Engineering, University of 


\section{Reading}

- Hughes, D., Williams, T. \& Zhaomin, R (2012). Is incentivisation significant in ensuring successful partnered projects. Engineering, Construction and Architectural Management, 19(3), 306-319. Crossref

- International Law Office (2003). Target Cost Contracts - the Lawyer's Perspective. Retrieved 12 March, 2017, from http:/www.internationallawoffice.com/Newsletters/Constr uction/United-Kingdom/Shadbolt-Co/Target-Cost-

Contracts-the-Lawyers-Perspective

- Kwawu, W. and Laryea, S. (2013). Incentive contracting in construction. In: Smith, S.D and Ahiaga-Dagbui, D.D (Eds) Procs 29th Annual ARCOM Conference, 2-4, Reading, UK, Association of Researchers in Construction Management, 729-738.

- Lewedon, S. (n.d). The Use of NEC: Engineering and Construction. Retrieved 15 August, 2017, from https://www.waterways.org.uk/pdf/restoration/the_use_of_ nec_engineering_and_construction_contract

- McInnis, A. (2001). The New Engineering Contract: A legal Commentary. London: Thomas Telford Publishing. $\underline{\text { Crossref }}$

- Perry, J., G. and Barnes, M. (2000). Target Cost Contracts: an analysis of the interplay between fee, target, share and price. Engineering, Construction, and Architectural Management, 7(2), 202-8. Crossref

- Perry, J., G. and Thompson, P., A. (1982). CIRIA Report 85; Target cost-reimbursable construction contracts. CIRIA: London.

- Pinsent Masons. (2016). Innovation in the Supply Chain. Theory and practice of innovation in construction. Retrieved 22 March, 2017, from https://www.pinsentmasons.com/PDF/2016/Innovation-inthe-supply-chain.pdf

- Rawlinson, S. (2007). Procurement: Target price contracts. Retrieved 10 March, 2017, from http://www.building.co.uk/procurement-target-pricecontracts/3095062.article

- Reynolds Porter Chamberlain [RPC]. (2013). Cost Overruns in Target Cost contracts. Retrieved 10 March, 2017, from https://www.rpc.co.uk/perspectives/builtenvironment/costs-overruns-in-target-costs-contracts

- RICS. (2014). RICS guidance note, UK; Appropriate contract selection (1st ed.). Royal Institution of Chartered Surveyors (RICS): Coventry, UK.

- RICS. (2017). Working with Target Cost Contracts. Retrieved 16 April, 2017, from http://www.rics.org/uk/training-events/trainingcourses/working-with-target-cost-contracts-/london121/

- Rose, T. and Manly, K. (2010). Client recommendations for financial incentives on construction projects. Engineering, Construction and Architectural Management, 17(3), 252$267 \underline{\text { Crossref }}$

- Scottish Futures Trust [SFT]. (2016). Review of Scottish Public Sector Procurement in Construction. Retrieved from http://www.scottishfuturestrust.org.uk/files/publications/G uidance_on_Procurement_Strategy_16_17_18_Final_26Ju ly16.pdf

- Tirole, J. (1986). Procurement and renegotiation. Journal of Political Economy, 94(2), 235-9. Crossref

- Weitzman, M., L. (1980). Efficient incentive contracts.
Quarterly Journal of Economics, 94(4), 719-730. Crossref

- Williams, T., Williams, M. and Ryall, P. (2013). Target cost contracts: adopting innovative incentive mechanisms to improve the project delivery process. In: Smith, S.D. and Ahiaga-Dagbui, D.D (Eds) Procs 29th Annual ARCOM Conference, 2-4, Reading, UK, Association of Researchers in Construction Management, 759-768.

- Wamuziri, S. and Seywright, A. (2005). Risk sharing and effective incentives in collaborative procurement. In: Khosrowshahi, F. (Ed.), 21st Annual ARCOM Conference, 7-9 September 2005, SOAS, University of London. Association of Researchers in Construction Management, Vol 2, 1175-84.

- Wood, G. (2005). Partnering practice in the relationship between clients and main contractors. RICS Research paper series. 5(2), 19. 